Article History:

Submitted:

27 April 2021

Reviewed:

2 May 2021

4 May 2021

Edited:

24 May 2021

Accepted:

6 July 2021

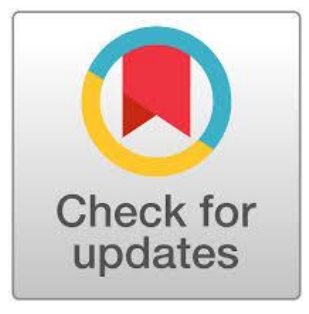

\section{A Qualitative Research on Self-Regulation Practices of ELT Students in Reading Class}

\author{
Harsya Danang Pradana ${ }^{*}$, Ouda Eda Tena \\ Sanata Dharma University, Indonesia \\ ${ }^{*}$ Corresponding author's email: $\underline{\text { haretranslations@gmail.com }}$
}

DOI: https://doi.org/10.18196/ftl.v6i2.11625

\begin{abstract}
This paper investigates the self-regulation practices in reading classes among students from a private university in Yogyakarta. In an era where students and their thinking process are the centers of the teaching and learning process, each student's metacognition skills need to adjust the teaching methods used inside and outside the classroom. To that end, students must be aware of their metacognitive skills and self-regulating behaviors. The research method used in this paper was the quantitative method. The researchers used the interview and focused group discussion (FGD) method on gaining information regarding students' awareness of their metacognitive skills and self-regulation habits. The participants were students from a predetermined private university in Yogyakarta, where the reading classes are known to be studentcentered. The results showed that while the students could create strategies and reflect upon said strategies, they still lacked a critical component of self-regulation, namely the preparation phase. This discovery means that the students need to be aware of the importance of preparing to meet specific goals and self-motivation.
\end{abstract}

Keywords: Metacognition; self-regulation; Reading; English language education students 


\section{Introduction}

\section{Background of the Research}

The advent of the 4.0 industrial revolution has connected the people of the world. With the presence of a digital world, people have been more connected to each other than ever before. Naturally, this has affected many aspects of our lives, including education. While it has not been the paradigm shift, it was prophesized in the 1980s. It has nonetheless changed - for better or worse - the face of education (Mirzajani, Mahmud, Ayub, \& Wong, 2016). Universities are beginning to implement e-learning facilities in their web pages to positive results, allowing them access to learning materials and tasks from the comfort of one's home (Cole et al., 2014). While some teachers are still struggling to implement ICT in their classes, ICT in classrooms is almost universally regarded as inevitable, even by the teachers (Sánchez, Marcos, González, \& GuanLin, 2012).

Some lecturers have been exploring and implementing student-centered methods into their classroom environment (Robinson, Neergaard, Tanggaard, \& Krueger, 2016). For higher education classes where the lecturers are not always available in classes, the students need to learn by themselves. However, students are more reluctant to ask others about learning the older they are (Dunn, Rakes, G. C., \& Rakes, T. A., 2014), which may lead to clueless university-level students using ineffective learning strategies or any strategy at all. However, as Presley stated that students develop self-assessment skills, although the process takes time (as Cited in Mbato, 2013).

Knowing the students' metacognitive skills and ability to self-regulate is essential to understand their learning capability. If the students know their limits and the strategies that work for them, they can learn better (Mega, Ronconi, \& De Beni, 2014). Students who can self-regulate can develop adequate language skills in language learning using the appropriate strategies (Mbato, 2013). When a self-regulated student reads a text, they involve themselves in "Constructive responsive reading", where they read with a articular purpose and actively construct meanings from the text (van Kraayenoord, 2010). 
This research determines self-regulation among English Language Education Students from a private university in Yogyakarta. During the researchers' time as a student in that university, lecturers at the private university implement student-centric learning methods in their teaching and learning method. Sometimes, the lecturers have to be away from the class, which requires them to learn independently. The researcher did this research to know if these students' methods fit their learning habits and help them learn.

\section{Importance of the Study}

This study provides insight into students' self-regulation practices from a pre-determined private university in Yogyakarta, where the students are considerably older and more mature. In other words, they are beyond their critical period hypothesis age. Specifically, this research inquired the self-regulation practices of students from the English Language Education Department, pre-service teachers training to become researchers. This research focused on the self-regulation skills the students use for reading activities to narrow the field. According to Noursi and Dhabi (2016), reading is one of the most basic yet essential skills for an English Learner.

\section{Past Studies and Gaps of the Research}

Past studies regarding pre-service teachers and self-regulation have been plentiful and varied. These range from ones researching the connection between self-regulated learners and their understanding of self-learning behaviors (Buzza \& Allinotte, 2013) to a long-spanning study of self-regulation for ICT learning tools (Armakolas \& Mikroyannidis, 2019). While there have been considerable research connecting pre-service teachers and the concept of self-regulation, what makes this research different from the others is its in-depth approach to the three components of self-regulation, according to Zimmerman (2010) namely preparation, monitoring, and self-reflection.

\section{Research Question:}

The research question for this research is: How is the practice of self-regulation in reading classes among the English language education students of a private university in Yogyakarta? 


\section{Research Outline}

The research paper is outlined as a regular research article. The first section will be the introductory section, containing the background of the research and the research question. The second section of the paper is the literature review. The literary sources cited in this research are mentioned and grouped into different research components. It includes metacognition, selfregulation, reading, self-regulation in ESL classes, and pre-service teachers and self-regulation. The literature review also contains previous, similar research projects that took place before this research article. The third section is the research method, where the reader can find details on how this research was conducted. The fourth section contains the findings and discussions, and the final section is the conclusion.

\section{Literature Review}

\section{Metacognition}

Metacognition has been referred to as "thinking about the contents and the processes of one's mind (Winne \& Azevedo, 2019). It is a necessary skill for learners to possess, allowing for a more in-depth understanding of the subject. Recently, there has been an increased interest in developing metacognition for learning (Cleary, Velardi, \& Schnaidman, 2017) and other aspects of life such as analytical thinking (Thompson \& Johnson, 2014). In addition, metacognition can better understand current collaborative learning environments (Garrison \& Akyol, 2015).

Winne and Azevedo (2019) in the Metacognition Cambridge Handbook mentioned a framework for understanding metacognition of the knowledge of cognition and regulation of cognition. According to Winne and Azevedo (2019), knowledge of cognition consists of declarative (factual information and concepts of a task), procedural (details on how to apply said information and concepts), and conditional knowledge (ongoing assessment of understanding, tasks, and goals). Meanwhile, regulation of cognition includes planning, monitoring, and evaluating plans and strategies that suit one's learning habits. 


\section{Self-Regulation}

Self-regulation is the active usage of strategies to attain academic goals, generally shown by a motivated approach to learning (Woogul, Myung-Jin, \& Bong, 2014). In addition to being aware and able to perform metacognitive processes, students capable of self-regulation are also mindful of the two other parts of self-regulation, namely motivation and behavior. Metacognitively, these students can devise plans, observe, and see how those plans have successfully been implemented on themselves. Motivationally, the students see themselves as competent and willing to learn. Behaviorally, these students can create an environment that promotes learning.

Zimmerman is widely considered the father of metacognition, further detailed the process of self-regulation into three phases: forethought, performance, and self-reflection (Zimmerman, Schunk, \& DiBenedetto, 2017). These phases occur during each step of the learning process. The forethought phase, where the learner sets a goal, plans strategies, and increases their motivation, appears before the learning process. The performance phase occurs during the learning process. The self-reflection is where the students see if the strategies are practical and adjust to the stated strategy. It takes place after the learning phase. Students who are capable of performing all three steps of self-regulation are called "self-regulated students". Naturally, all students have different degrees of self-regulation, and some factors can influence self-regulation, from the regulation of emotion to self-control (McClelland, Geldhof, Cameron, \& Wanless, 2015).

When properly motivated, self-regulated students use specific strategies that employ selfefficacy (Woogul et al., 2014). In layman's terms, they use proper techniques. Different students may employ various techniques to approach similar issues (Wael, Asnur, \& Ibrahim, 2018), and those who are self-regulated chose strategies that fit their learning style. Application of selfregulated learning intervention to a learning environment show improved achievement scores and is considered a socially valid intervention (Cleary et al., 2017). It shows the increasing students' awareness regarding the concept of self-regulated learning. 


\section{Reading Skills}

Reading is a more complex linguistics skill because it requires a deep understanding of the material being read to extract meaning from the text (K. T. C. Chen \& S. C. L. Chen, 2015). Policymakers would like all teachers to use effective materials, which puts a good amount of pressure on the researchers. Reading is, essentially, an exercise to comprehend and construct meaning in a piece of text (van Kraayenoord, 2010). As such, psychological and educational research regarding reading mainly covers the strategic nature of reading. For example, the practice of reading comprehension. On paper, it is as simple as reading a text and understanding its meaning. However, many elements take place during reading comprehension, including motivation, vocabulary, cognitive strategy, and of course, metacognition and self-regulation (Israel, 2014).

\section{Metacognition in Reading}

According to van Kraayenoord (2010), the focus of instructing metacognitive and comprehension-related strategies should focus on teaching multiple strategies instead of just one method. Hence, the students can mix and match strategies. In her research, she listed seven strategies. The first one has Informed Strategies for Learning, which focuses on the declarative, procedural, and conditional knowledge of reading and the connected strategies to increase the students' learning comprehension. The second one is Reciprocal Teaching, which teaches four ways to comprehend a text - predicting, questioning, summarizing, and clarifying. The third one is the Direct Explanation of Strategies, where the teachers explain strategies to be used by the students and how the strategy can help them. The fourth one is Transactional Strategies Instruction, which promotes the idea that students are flexible and should choose various strategies that work for them. The fifth one, Concept Oriented Reading Instruction, emphasizes motivation and combines it with strategies. The sixth one, Collaborative Strategic Reading, uses multiple comprehension strategies alongside collaborative learning. The final one, Peer Assisted Learning Strategies, utilizes verbal materials and makes the students work together to address issues. Some of these strategies can and should be used with each other. 


\section{Self-regulation in ESL Classes}

Self-regulation in ESL classes broadly covers two categories: the students' overall ability to self-regulate their learning or the students' display of self-regulation while learning a new skill. Research regarding the first category would investigate if the students displayed self-regulatory characteristics (Fadda, 2019) or the effectiveness of self-regulation in learning (Vasu, Mei Fung, Nimehchisalem, \& Rashid, 2020). On the other hand, research regarding the second category would see how the students self-regulate themselves when exposed to a new skill (Fathi, Ahmadnejad, \& Yousofi., 2019). The second category can sometimes reveal further information; research done by Fathi et al. (2019) regarding the introduction of blogs into EFL writing instruction showed that the students' self-efficacy decreased despite their increased motivation to learn.

\section{Pre-service Teachers and Self-regulation}

Research regarding pre-service teachers has shown self-regulatory strategies and metacognition. Buzza and Allinote (2013) analyzed student teachers and their ability to establish self-regulatory learning. The result showed the importance of teaching student teachers the concept of self-regulated learning. Meanwhile, A research by Alenazi showed that pre-service teachers could employ metacognitive strategies to learn the context and skills required to complete a course (Alenazi, 2017). The addition of new skills can add to the student teacher's ability to self-regulate, giving them more avenues to improve their self-efficacy (Armakolas \& Mikroyannidis, 2019).

\section{Related Research}

To put this study into context, the researchers have included three studies regarding selfregulation strategies in this research. The first study was conducted by Broadbent and Poon (2015) regarding the self-regulated learning strategies \& academic achievement in online higher education learning environments. This study found that the students employ strategies to achieve academic success, including time management, metacognition, effort regulation, and critical thinking (Broadbent \& Poon, 2015). Their study was done on a university level through an online survey, unlike this current research. The researchers did not specify the faculties or departments of the students. Another study regarding self-regulation strategies was done by 
Cosentino (2017), which inquired about self-regulation strategies on reading comprehension, motivation for learning, and self-efficacy with struggling readers. The study showed that the struggling leaders had strategies to help with reading (Cosentino, 2017). Cosentino's study was done to inquire about self-regulation strategies for reading, but there are some differences between said and this research. Cosentino's study used a quantitative instrument survey, while this research used two qualitative methods: questionnaire and focus group discussion. In addition, Cosentino's respondents had difficulties with the reading activity, while the study participants may or may not have problems. The third study was done by Liu et al. (2014), regarding the college students' motivation and learning strategies profiles and academic Achievement. The main difference between this study and this research is the methods used. Their research uses the quantitative method, while this research uses the qualitative approach.

\section{Methodology}

This research used a qualitative research method, specifically the descriptive qualitative design. Descriptive qualitative design is a research design used to identify descriptive qualities in a specific ethnic group (Creswell, 2012). Since the researchers wanted to know a certain quality in the students, namely the self-regulatory strategies of the students for reading classes, the qualitative method will be used.

This research took place in a private university in Yogyakarta. One of the researchers was a student there and has been familiar with its accessibility, student body, and lecturers. The researcher knew that the participants had taken reading classes in the first and second semesters, meaning that they were likely to have developed some strategies for those classes. In addition, the researcher's familiarity will make the data-gathering process for this research more accessible. The participants of this research will be students from the 2016 batch. They are chosen because, by the time this research took place, they would have taken the mandatory reading classes for the university, which makes them likely to have developed a strategy for it. The sampling method used in this research will be the purposive sampling method. This method is used if the researcher wants to draw participants with specific criteria (Taherdoost, 2018). The only standard for the participants of this study is that the participants must have attended the reading classes of the university. 
To gather the necessary data for the research, the researchers employed several different data collection methods. The first method is the questionnaire method. Although the questionnaire method is usually used in quantitative study projects, some qualitative studies also use questionnaires for long-range or wide-range participants (Travers, Morisano, \& Locke, 2015). The second method used by the researchers is the Focus Group Discussion or FGD. The Focus Group Discussion method is used when the researcher is looking to obtain data from a selected group of individuals instead of a statistic representative of the broader population (Nyumba, Wilson, Derrick, \& Mukherjee, 2018). The researchers employed the focus group discussion method to find additional details regarding the participants' reading strategies. To create the questions for the questionnaire and the FGD, the researchers looked into Zimmerman's three phases of self-regulation (Zimmerman et al., 2017). The three phases are forethought, where the learner analyzes the task and sets their goals; performance, where the learners start the learning process and apply the strategies; and self-reflection, where the learners see where if their strategies have been successful and improves upon it (Zimmerman et al., 2017). Because the researchers plan on investigating the reading strategies of the participants, the questions were adjusted accordingly.

The data collection method started with the researchers contacting potential participants through the WhatsApp application. Since qualitative researches do not have a set limit of participants (Cohen, Manion, \& Morrison, 2011), the researchers asked if any students in the shared group are willing to become participants. Through this method, the researchers gathered five participants. The five participants were chosen because of their availability and one of the researchers' familiarity with them: having been students in the private university for some time, the students have taken the mandatory reading classes of said university. Initially, the researchers aimed to employ a face-to-face interview method to conduct open-ended interviews with each participant. However, the researchers switched to the questionnaire and focused group discussion method because of better data validity. After the researchers had gathered participants for the research, the researchers sent them questionnaires to answer. The questionnaire is designed similar to a set of open-ended interview questions, and the items of said questionnaires are designed to gather data relevant to the research questions (Arsel, 2017). After the questionnaires were sent, the researchers also asked the students to conduct a focus group 
discussion. To make it convenient to the participants, the researchers came to the students' location, namely their private university, to run the focus group discussion. The researchers asked similar questions to see if the participants had something to add to the information. The focus

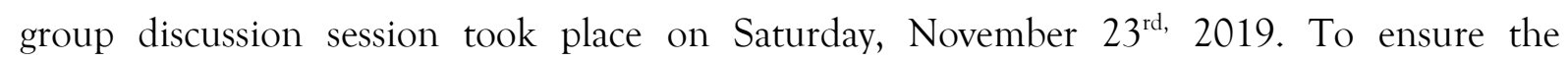
participants' identities, they were each assigned a letter instead of a name. Those letters are $\mathrm{D}, \mathrm{S}$, $\mathrm{H}, \mathrm{R}$, and $\mathrm{N}$.

For validity reasons, the recordings for each questionnaire were transcribed into a Microsoft Word document. For the coding method, the researchers used the Open, Axial, and Selective coding methods. Coding is a method to catalog and sort the interview results or other data gathering methods (Cohen et al., 2011). The first step of coding is open coding, which will be done by labeling the texts to categorize them. Then, axial coding will be performed. Axial coding involves labeling groups of available codes that are similar in meaning. Third, selective coding is to see which data is most relevant to answer the research questions. Finally, the information was written down in a report that can be seen in the next section of this research paper.

\section{Findings}

In the beginning, the researchers set out to find out the self-regulation habits and practices employed by English language education department students in reading classes at a private university in Yogyakarta. It came from the desire to see the students succeed in the post4.0 industrial era when student-centered learning expects students to learn by themselves. If the students are capable of performing self-regulatory practices, they will adapt to a period of selfstudy. The study focuses on the students' practices during reading classes and assignments given in said reading classes to narrow the scope of the research and make it more focused. When sufficiently self-regulated, students of a particular language can develop their linguistic skills and assign meanings to what they read. As such, the researchers used the research question: "How is the practice of self-regulation in reading classes among the English language education students at a private university in Yogyakarta?". The research used an online questionnaire and an offline focus group discussion session with five private university students. After distributing the online questionnaire and conducting a focus group discussion to gather relevant data, the acquired data 
were analyzed through multiple phases of coding, namely open, axial, and selective coding, before the findings from those coding phases.

According to Zimmermann (2010), self-regulation is divided into three phases: preparation or forethought, monitoring or performance, and self-reflection. To learn about the level of self-regulation employed by English Language Education Department students of a private university in Yogyakarta, the researchers created a questionnaire. They hosted a focused group discussion to gather data from the participants. The researchers made their set of questions and focus group discussions, and they modeled the questionnaire and the focus group discussion on the three phases of self-regulation. After the data gathered and analyzed, the researchers found that all research participants employed an incomplete version of self-regulation. In brief, none of the participants utilized the preparation phase of self-regulation, meaning that they did not tailor their strategies to what they expect to learn. However, all the research participants engage their set of strategies when learning reading or performing reading exercises and mentioned their strategy, showing that they employed the monitoring phase of self-regulation. Finally, all except one participant felt that their strategy could be improved. Those who mentioned that they could improve their strategy even said they would improve their strategy on the spot, showing that they could perform self-reflection. Details on which participants fulfill which criteria of self-regulation can be seen in Table 1, and more detailed findings regarding which entry

\section{Preparation}

The preparation phase involved setting goals or performing acts of self-motivation before the beginning of the activity. In the questionnaire and the focus group discussion, none of the research participants mentioned that they set their learning goals or increase their motivation to do reading activities or exercises. None of the participants fulfilled the criteria of the preparation phase of self-regulation. Even though they employed strategies in learning reading and claim to improve said strategies, they did not analyze the task before the learning process, set learning goals, or increase their motivation. The participants did not have a good enough grasp of the preparation phase, meaning that they treated any activities as if they were not necessary. The amount of self-regulation employed by a learner can be affected by many factors, including emotion (Mega et al., 2014). The incomplete self-regulation process displayed 
by the participants could be caused by the participants' lack of any particular feeling towards the activity, treating them as another activity without knowing the end goal.

Table 1. Phases of self-regulation employed by English Language Education Students of a Private university in Yogyakarta on Reading Classes and Activities

\begin{tabular}{lccl}
\hline & Preparation & Monitoring & Self-reflection \\
\hline D & No & Yes & Yes \\
S & No & Yes & Yes/No \\
H & No & Yes & Yes \\
R & No & Yes & Yes \\
N & No. & Yes & Yes \\
\hline
\end{tabular}

\section{Monitoring}

The monitoring phase was done during the activity itself, and it usually involved strategies to deal with said activities to create the desired outcome. This step involved experimenting with said strategies on the spot, switching to different strategies to respond to changing events. In contrast with their lack of preparation, the participants employed several different strategies for performing activities in the reading class, showing that they had a good grasp of the monitoring phase of self-regulation. All participants used strategies during reading, and some of them even try to experiment with them. Strategies employed by the participants gathered during the research include memorization (P1.2 Every time I read something I write down...using small notes...then I memorize them), creating keynotes (P1.3 In my case, I write it down and use the Stabilo...use a pen on important points and make keynotes. I read them all first, and I underline them. Once I know the keynotes, like "Oh, that's how it is, that's what connects with this...) and repetition (P2.1 If I read something and I find a word I do not understand, I will translate it and then read it again...like that) Employing different strategies for different activities is a proof that the participants are motivated enough to learn (Woogul et al., 2014), especially when they 
monitor their learning to see if their strategy had worked. The research proved that the participants were motivated to learn, as they all devised their strategies.

\section{Self-reflection}

The last part of the self-regulation circle is self-reflection. The students evaluate their strategies after being employed and create adjustments to improve their strategies for the future. Unlike the changes performed in the monitoring phase, these changes were after the dust settled and the activity's outcome. Out of the five participants of this study, all participants feel that their strategies have helped them perform reading activities in reading classes. During the focused group discussion session, one of the participants finished presenting her thesis proposal to a lecturer board. When asked if the strategies she had employed were helpful for her, she stated that it helped her a lot (P1.4 Helpful, like that's what I did on the presentation). Despite this, only four of the participants thought that their strategies could be improved. The participant said otherwise, stating that she could not find any ideas on improving her strategies (P2.3 I can't...).

On the other hand, four participants felt that their strategy could still be improved. Some mentioned ways to improve them, such as creating an audio recording of the memorized items (P5.4 Make it into audio form...maybe), taking important points (P1.5 I would take the important points, so I don't feel nervous...Like that) and underlining her writing (P3.4 As for me...I think...I'll add...like when I know the meaning and things, I'll underline the important things). The four participants were capable of judging themselves and their strategies and reacting if said judgments found themselves or their strategies inadequate. Self-reflection is an essential part of the learning process, and students who can employ self-reflection properly will be able to use their resources more effectively (Chen, Chavez, Ong \& Gunderson, 2017). Judging from the fact that all five participants were aware of their strategies and four out of five participants could improve their strategy, English language students at the private university could self-reflect on reading classes and exercises. 


\section{Journal of Foreign Language Teaching and Learning}

Volume 6, No. 2, July 2021

Available online at: https://journal.umy.ac.id/index.php/FTL/issue/view/786

e-ISSN: 2580-2070, p-ISSN: $2527-7650$

Table 2. Self-regulation practices of English Language Education Students from a Private University in Yogyakarta during Reading Sorted by Phases

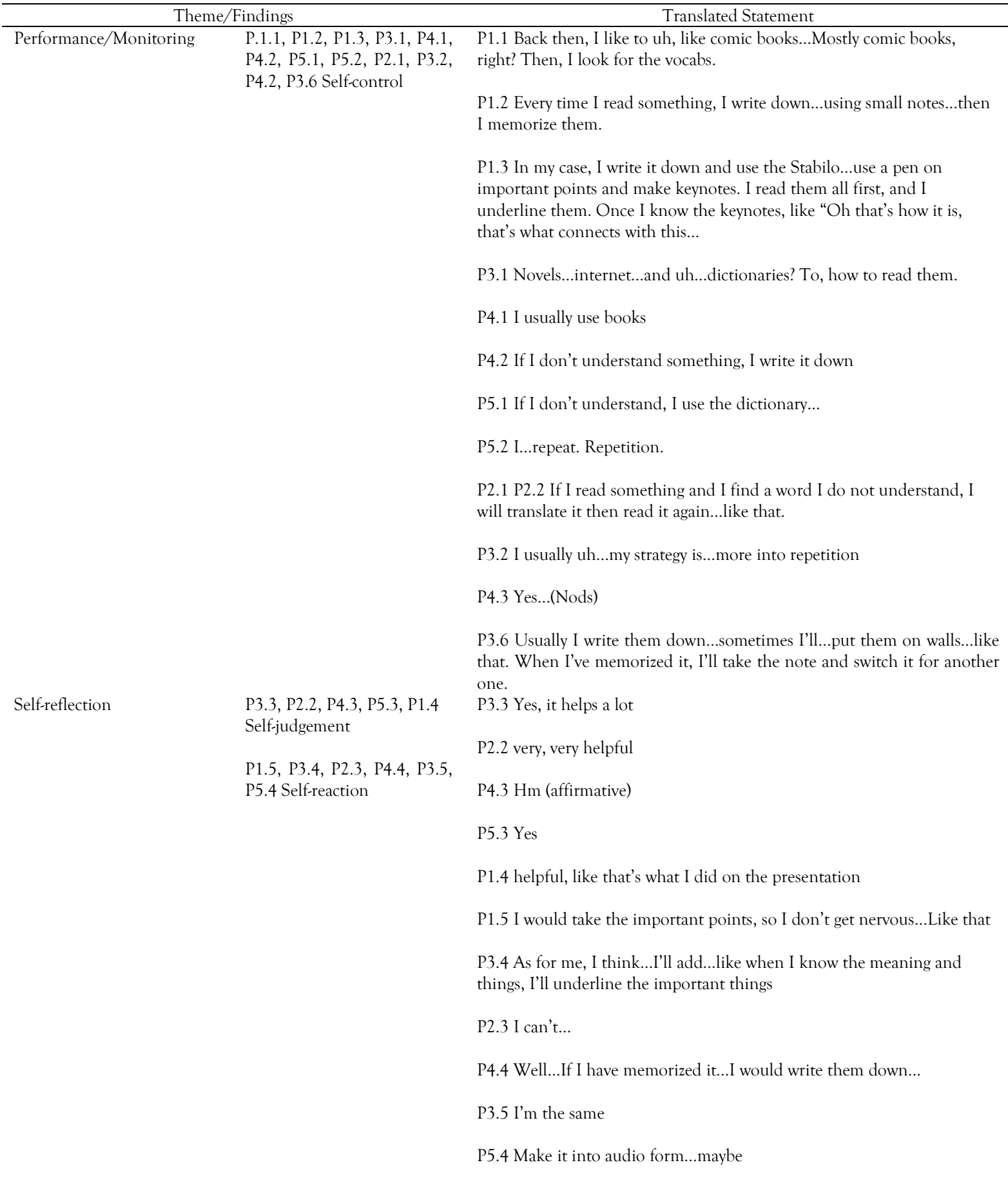




\section{Discussion}

At first, the researchers set out to find the self-regulatory practices employed by students at a private university in Yogyakarta during reading classes and activities to find out if they can adapt and survive in the post-4.0 industrial revolution classroom at the center of the learning process. To this end, the researchers employed two different methods, namely questionnaires and focus group discussion, to gather data and translate them into the research findings. The findings concluded that the English language education students at this private university in Yogyakarta employed an incomplete variation of self-regulation when performing reading activities, monitoring their learning strategies, and reflecting upon said strategies, but not prepare them. While they used strategies in learning, some could not improve upon said strategies, and none of them employs any self-motivation increase or task analysis. According to Cosentino's (2017) study, this lack of self-regulation perfection can be caused by their lack of knowledge, exposure, and experience with proper self-regulation strategies. It falls to the educators to explain self-regulation to the students and encourage them to self-regulate their studies. In addition, the types of self-regulatory strategies employed by the students have different effects on academic performance. According to Broadbent and Poon's (2015) research, the most positive effects are time management, metacognition, and critical thinking. While elaboration, rehearsal, and organization have the least amount of effect. This fact underlines self-regulation employed by the students and which method should be employed to improve academic performance. The students' employed strategies could improve upon them. They had some degree of understanding of metacognition. Still, the strategies themselves (such as repetition and memorization) are included in rehearsal, one of the methods with the lowest effect. Finally, research by Liu et al. (2014) mentioned the importance of needs satisfaction in self-regulated learning behavior. It highlights the flexibility of strategic drafting to fulfill certain needs. It is the principle employed by the participants when drafting their strategy. They aim to perform well in their reading activities, and their strategies were created to fulfill that aim. However, only aiming to perform well is not enough to complete Zimmermann's trinity of self-regulation. However, despite being self-regulatory to a degree, the English language students at this private university still lack one important part in the process of self-regulation: the preparation part. While they are fully capable 
of creating strategies, experimenting with them on the fly, reflecting on said strategies, and changing them for the better, they still lack self-motivation and do not perform any task analysis.

Having strategies is one thing, but having a proper strategy is another. All three parts of self-regulation must be presented and practiced properly, or the process will be incomplete. In the case of the participants, lack of preparation means that they do not have a proverbial starting line in their journey; They do not recognize any clear motivation for the strategy, and they treat the activity like any other activity. The importance of motivation can be seen because the participants are motivated enough to create strategies for the monitoring phase of self-regulation but not enough to have set goals before the activity, making them miss the preparation phase. Thankfully for the participants, there are several ways to increase the participants' motivation, one of them mentioning lack of progress. While this method may seem cruel at first, research by Koo and Fishbach (2014) stated that unaccomplished goals could be a source of motivation for students. By letting the students know that the goals set are still unaccomplished, they can feel more motivated, thereby fulfilling one of the conditions for the preparation phase (Koo \& Fishbach, 2014). At the university level, this is usually done in the first meeting of the class, a practice that, coincidentally, is employed in the private university where this research takes place. In the first meeting of the class, lecturers would explain the class syllabus, showing the students what to expect from the class, what activities they will perform, and what skills they will have learned at the end of the class. The researchers believe that by leveraging this activity, a proper way to motivate students and have them analyze the task presented to them can help them practice the preparation phase and complete the three phases of self-regulation.

Finally, any teacher, educator, or lecturer needs to understand the importance of selfregulation, especially in the preparation phase. Considering that the participants of this class themselves are pre-service teachers, their lack of understanding of the preparation phase can be a glaring flaw when deciding to enter the teaching world. Any educator must motivate their students properly, or better yet, make the students motivate themselves. Considerable research related to self-regulation showed that pre-service teachers could do it (Fadda, 2019). If the teachers do not know how to motivate themselves, they may find it difficult to motivate others. The same principles apply to the two other branches of self-regulation. Suppose the students do 
not know how to properly strategize to solve their activities or do not know how to perform selfreflection and adapt their strategies. In that case, they will struggle to learn by themselves, defeating the entire purpose of student-centered learning. In this era where technology has taken over the classroom for better or worse, we must trust our students to learn by themselves. However, this does not mean our role as educators is over. Teachers have shifted into a support position, where in addition to directing our students, and must support and encourage them to learn independently. Gone are the days of teachers standing in front of a blackboard, explaining and repeating phrases with a face caked with chalk dust. Technology has allowed teachers to educate and support students in more ways than ever, and with the constantly improving world of education, they must make sure that said technology is used in the right way, where the students can improve themselves.

\section{Conclusion}

This research was intended to see the self-regulatory practices of English Language Education Students of a private university in Yogyakarta to see if they can self-regulate their studies in a student-centered classroom where they are the main actors of the activities. After the research has concluded, the researchers found that the self-regulatory capabilities of English Language Education students in this particular private university still lacked, particularly in the preparation department. The students were capable of creating a strategy and monitoring said strategy. Still, their lack of goal-setting and self-motivation increase leads the researchers to believe that the self-regulation capabilities of these students could still be improved. Since this research is limited to the reading class, future research should encompass the other three primary English language skills. In addition, the preparation phase of self-regulation must also be delved further to make sure that students are familiar with all three phases of self-regulation, not just two out of three steps. Finally, as students age, they are more reluctant to seek help from others. Hopefully, future research can help the students without making them feel more reluctant to seek help. 


\section{References}

Alenazi, A. (2017). How Pre-Service Teachers Learn: An Investigation of Motivation and SelfRegulation. International Journal of Learning, Teaching and Educational Research, 16(10), 5871. https://doi.org/10.26803/ijlter.16.10.5

Armakolas, S., \& Mikroyannidis, A. (2019). Self-regulation in pre-service teacher training Conference. Open Research Online, December 2019.

Arsel, Z. (2017). Asking questions with reflexive focus: Atutorial on designing and conducting interviews. Journal of Consumer Research, 44(4), 939-948. https://doi.org/10.1093/jcr/ucx096

Broadbent, J., \& Poon, W. L. (2015). Self-regulated learning strategies \& academic achievement in online higher education learning environments: A systematic review. Internet and Higher Education, 27, 1-13. https://doi.org/10.1016/j.iheduc.2015.04.007

Buzza, D., \& Allinotte, T. (2013). Pre-service Teachers' Self-Regulated Learning and their Developing Concepts of SRL. Brock Education Journal, 23(1). https://doi.org/10.26522/brocked.v23i1.353

Chen, K. T. C., \& Chen, S. C. L. (2015). The use of EFL reading strategies among high school students in taiwan. The Reading Matrix: An International Online Journal, 15(2), 156-166.

Chen, P., Chavez, O., Ong, D. C., \& Gunderson, B. (2017). Strategic Resource Use for Learning: A Self-Administered Intervention That Guides Self-Reflection on Effective Resource Use Enhances Academic Performance. Psychological Science, 28(6), 774-785. https://doi.org/10.1177/0956797617696456

Cleary, T. J., Velardi, B., \& Schnaidman, B. (2017). Effects of the Self-Regulation Empowerment Program (SREP) on middle school students' strategic skills, self-efficacy, and mathematics achievement. Journal of School Psychology, 64(April), 28-42. https://doi.org/10.1016/j.jsp.2017.04.004

Cohen, L., Manion, L., \& Morrison, K. (2011). Research Methods in Education.

Cole, M. T., Shelley, D. J., \& Swartz, L. B. (2014). Online instruction, e-learning, and student satisfaction: A three year study. International Review of Research in Open and Distance Learning, 15(6), 111-131. https://doi.org/10.19173/irrodl.v15i6.1748

Cosentino, C. L. (2017). the Effects of Self-Regulation Strategies on Reading Comprehension, Motivation for Learning, and Self-Efficacy With Struggling Readers. 68. http://repository.wcsu.edu/educationdis/68

Creswell, J. (2012). Educational Research.

Fadda, H. Al. (2019). The Relationship Between Self-Regulations and Online Learning in an ESL Blended Learning Context. English Language Teaching, 12(6), 87. 
https://doi.org/10.5539/elt.v12n6p87

Fathi, J., Ahmadnejad, M., \& Yousofi, N. (2019). Effects of blog-mediated writing instruction on 12 writing motivation, self-efficacy, and self-regulation: A mixed methods study1. Journal of Research in Applied Linguistics, 10(2), 159-181. https://doi.org/10.22055/rals.2019.14722

Garrison, D. R., \& Akyol, Z. (2015). Toward the development of a metacognition construct for communities of inquiry. Internet and Higher Education, 24, 66-71. https://doi.org/10.1016/j.iheduc.2014.10.001

Israel, S. E. (2014). Handbook of Research on Reading Comprehension. In Handbook of Research on Reading Comprehension. https://doi.org/10.4324/9781315759609

Koo, M., \& Fishbach, A. (2014). Dynamics of self-regulation: How (un)accomplished goal actions affect motivation. Motivation Science, 1(S), 73-90. https://doi.org/10.1037/23338113.1.s.73

Mbato, C. L. (2013). Facilitating EFL learners' self-regulation in reading : implementing a metacognitive approach in an Indonesian higher education context. 1-252.

McClelland, M. M., Geldhof, G. J., Cameron, C. E., \& Wanless, S. B. (2015). Development and Self-Regulation.

Mega, C., Ronconi, L., \& De Beni, R. (2014). What makes a good student? How emotions, self-regulated learning, and motivation contribute to academic Achievement. Journal of Educational Psychology, 106(1), 121-131. https://doi.org/10.1037/a0033546

Mirzajani, H., Mahmud, Rosnaini, F., Ayub, A., \& Wong, S. L. (2016). Teachers' acceptance of ICT and its integration in the classroom. Quality Assurance in Education, 24(1), 26-40. https://doi.org/10.1108/QAE-06-2014-0025

O.Nyumba, T., Wilson, K., Derrick, C. J., \& Mukherjee, N. (2018). The use of focus group discussion methodology: Insights from two decades of application in conservation. Methods in Ecology and Evolution, 9(1), 20-32. https://doi.org/10.1111/2041-210X.12860

Robinson, S., Neergaard, H., Tanggaard, L., \& Krueger, N. (2016). New horizons in entrepreneurship: from teacher-led to student-centered learning. Education and Training, 58(7-8), 661-683. https://doi.org/10.1108/ET-03-2016-0048

Sánchez, A.-B., Marcos, J.-J. M., González, M., \& GuanLin, H. (2012). In Service Teachers' Attitudes towards the Use of ICT in the Classroom. Procedia - Social and Behavioral Sciences, 46, 1358-1364. https://doi.org/10.1016/j.sbspro.2012.05.302

Taherdoost, H. (2018). Sampling Methods in Research Methodology; How to Choose a Sampling Technique for Research. SSRN Electronic Journal, September. https://doi.org/10.2139/ssrn.3205035 
Thompson, V. A., \& Johnson, S. C. (2014). Conflict, metacognition, and analytic thinking. Thinking and Reasoning, 20(2), 215-244. https://doi.org/10.1080/13546783.2013.869763

Travers, C. J., Morisano, D., \& Locke, E. A. (2015). Self-reflection, growth goals, and academic outcomes: A qualitative study. British Journal of Educational Psychology, 85(2), 224-241. https://doi.org/10.1111/bjep.12059

van Kraayenoord, C. E. (2010). The Role of Metacognition in Reading Instruction. Scandinavian Journal of Educational Research, 36(3), 211-221. https://doi.org/10.1080/0031383920360304

Vasu, K. A., Mei Fung, Y., Nimehchisalem, V., \& Md Rashid, S. (2020). Self-Regulated Learning Development in Undergraduate ESL Writing Classrooms: Teacher Feedback Versus Self-Assessment. RELC Journal. https://doi.org/10.1177/0033688220957782

Wael, A., Asnur, M. N. A., \& Ibrahim, I. (2018). Exploring Students' Learning Strategies in Speaking Performance. International Journal of Language Education, 2(1), 65. https://doi.org/10.26858/ijole.v2i1.5238

Winne, P. H., \& Azevedo, R. (2019). Metacognition. In Metacognition: The Cambridge handbook (pp. 63-87).

Woogul, L., Myung-Jin, L., \& Bong, M. (2014). Testing Interest and Self-Efficacy as Predictors of Academic Self-Regulation and Achievement. Contemporary Educational Psychology.

Zimmerman, B. J., Schunk, D. H., \& DiBenedetto, M. K. (2017). The Role of Self-Efficacy and Related Beliefs in Self-Regulation of Learning and Performance. In Handbook of Competence and Motivation, Second Edition: Theory and Application (pp. 313-333). 